\title{
Discovering the Health Promoting Potential of Fermented Papaya Preparation-Its Future Perspectives for the Dietary Management of Oxidative Stress During Diabetes
}

\author{
Jhoti Somanah ${ }^{1}$, Manish Putteeraj ${ }^{1}$, Okezie I. Aruoma ${ }^{2,3}$ and Theeshan Bahorun ${ }^{4, *}$ (i) \\ 1 School of Health Sciences, University of Technology, Mauritius, La Tour Koenig, Pointe aux Sables 11134, \\ Mauritius; mjbhugowandeen@umail.utm.ac.mu (J.S.); mputteeraj@umail.utm.ac.mu (M.P.) \\ 2 Department of Undergraduate Studies, College of Science and Integrated Health, Southern California \\ University of Health Sciences, Whittier, CA 90604, USA; oaruoma@calstatela.edu \\ 3 Department of Chemistry and Biochemistry, California State University Los Angeles, \\ Los Angeles, CA 90032, USA \\ 4 ANDI Center of Excellence for Biomedical and Biomaterials Research, University of Mauritius, \\ Réduit 80835, Mauritius \\ * Correspondence: tbahorun@uom.ac.mu; Tel.: +230-4675-582
}

Received: 24 July 2018; Accepted: 27 September 2018; Published: 28 September 2018

\begin{abstract}
The simplistic morphological characteristics of Carica papaya fruit or "pawpaw" should not be the cause for underestimating its potential as a nutraceutical. The market for papaya has been expanding at a staggering rate, partly due to its applicability as a biofortified product, but also due to its phytochemical properties and traditional health benefits. Papaya or formulations of fermented papaya promotion (FPP) display effective free radical scavenging abilities thought to be influenced by its phenolic, carotenoid, flavonoid, or amino acid profile. The antioxidant properties of FPP have been extensively reported in literature to potently target a broad spectrum of free radical-induced diseases ranging from neurological impairments, such as senile dementia, to systemic diseases, to its interference at the cellular level and the support of normal biological ageing processes. FPP has thus been extensively investigated for its ability to exert cellular protective effects and reduce oxidative stress via the mitigation of genetic damage, reduction of lipid peroxidation, and enzymatic inactivation in specific diseases. The focus of this review is to appraise the potential of oxidative stress reduction strategies of FPP and discuss its holistic approach in disease prevention and management, with a particular focus on diabetes and cancer. However, with the current lack of information surrounding its mechanism of action, this review wishes to set the stage and aspire researchers to more profoundly investigate molecular pathways related to how FPP can unequivocally contribute to wellness in an aging population.
\end{abstract}

Keywords: Carica papaya; fermented papaya preparation (FPP); free radical scavenging; antioxidant; oxidative stress; anti-diabetic; anti-carcinogenic

\section{Introduction}

Being favored for their unique flavor, texture, or health-promoting benefits, fermented foods can be prepared and consumed in a number of ways. One of the important outcomes of food fermentation is its enrichment with essential amino acids, vitamins, and minerals; for example, idli (an Indian cake made from Rhizopus oligosporous fermented rice and black-gram) contains high levels of thiamine and riboflavin [1]. Similarly, natto (a sticky soybean dish) is popular amongst the Japanese for its 
vitamin K2 [2], as is the Nepalese dish of Gundruk (fermented mustard, radish, and cauliflower leaves), which has a high ascorbic acid and fiber content, and tempeh, a popular fermented food in Indonesia that is rich in nutrients and active substances [3], with both having a continued consumer appeal worldwide. The process of fermentation coaxes microorganisms into degrading anti-nutritive compounds, making food more edible and digestible, thus augmenting the bioavailability of its health-protecting nutrients. Detoxification, on the other hand, is a sub-process of fermentation, which can render certain foods safer to eat, for example, in the case of cyanogenic glucoside removal from the cassava root by Geotricum candida and Cornibacterium lactii cultures [4].

Fermented papaya preparation (FPP) is a proprietary yeast fermentation product sold under the commercial trade name of Immun'Âge ${ }^{\circledR}$. FPP is a certified natural health product and has gained global recognition following its manufacture under the strictest food safety management systems (FSSC 22000 \& ISO standards) [5]. Fresh ripe fruit pulp of Hawaiian-grown Carica papaya is used for the fabrication of FPP, which is allowed to ferment in the presence of food-grade yeast for up to 12 months. The final product is granulated before being packaged and distributed. Although the general composition of FPP has been ascertained by the Japan Food Research Laboratory, recognition of the presence of several amino acids and novel uncharacterized oligosaccharides in FPP is suspected to be an outcome of the prolonged fermentation process [5]. Studies scrutinizing the therapeutic qualities of papaya fruit have accredited them to its remarkable free radical scavenging activity. At the same time, to explain the source of papaya's antioxidant activity, some authors correlate the latter to its polyphenolic content. Initial fractionation of FPP by Rimbach et al. [6] brought to light the different activity patterns of high- and low-molecular weight fractions with respect to superoxide anion scavenging and macrophage RAW 264.7 activation. Interestingly, Fibach and Ginsburg [7] pointed out that although the overall quantity of phenols in FPP is very low when measured in a salt solution, its levels can be boosted six-fold when assayed in saliva, albumin, mucin, or red blood cell suspensions in vivo. Chemical analysis by Japanese researchers on a fermented papaya preparation using capillary electrophoresis-time-of-flight mass spectrometry (CE-TOFMS) and liquid chromatography (LC-TOFMS) revealed the presence of several low-molecular weight phenolic acids, such as 2,5 dihydroxybenzoic acid, quinic acid, shikimic acid, and m-aminophenol [8]. Although the work of Fujita et al. [5] is amongst the few to shed light on the composition of a fermented papaya preparation, caution must be sought when comparing its outcomes to that of FPP. Disparity in terms of polyphenolic composition and bioactivity will vary as an obvious result of genetic differences between papaya species, cultivation practices, microclimates, and fermentation protocol [8-11]. Furthermore, despite controversy over the sophistication of present analytical technologies and the unelucidated components responsible for the activity of FPP, the authors are in agreement that the multifunctional properties of FPP cannot be singled out to a specific chemical, but rather to a synergistic interaction of its ingredients, which renders it a unique fermented functional food.

\section{The Concept of Oxidative Stress as a Unique Therapeutic Pathway by Nutraceuticals for the Management of Type 2 Diabetes}

Profound interest in the relationship between free radicals and oxidative stress in diabetes is an area attracting much attention from scientists. During type 2 diabetes, oxidative stress can emerge from the production of free radicals as a result of glucose auto-oxidation, protein glycosylation, low-grade inflammation, and from the metabolic breakdown of free fatty acids [12]. Although the quantity of free radicals generated through normal cellular metabolism is minute, they play a vital regulatory role in many biological processes $[13,14]$. Environmental factors such as air contaminants, exposure to heavy metals and pesticides, vigorous exercise, and infections are also potential sources of free radicals within the body [15]. Hyperglycemia-induced oxidative stress is believed to be closely associated with the impairment of antioxidant defense mechanisms, representing a central contribution to the onset, progression, and pathology of diabetes and its associated health complications. Defective insulin signaling pathways, degranulation, and accelerated apoptosis of pancreatic $\beta$-cells are tell-tale signs 
of severe oxidative stress in hyperglycemia states [16-18]. Strict weight loss and exercise regimes have been proved to be highly efficient in improving $\beta$-cell function, insulin sensitivity, and skeletal muscle oxidative capacity-emphasizing the necessity of maintaining body mass within acceptable levels $[19,20]$. However, with current sedentary lifestyles, this is an attitude that is unfortunately easier said than done.

Oxidative stress can rapidly overwhelm the activity of endogenous antioxidant enzymes, leaving the body prone to free radical attack, hence the implication of reactive oxygen species in the pathogenesis of several complications associated with diabetes, including heart disease, nephropathy, and retinopathy, is now widely accepted [21-23]. Conjointly, oxidative damage to the structure of DNA can impinge spontaneous mutations, trigger abnormal cell growth, or force premature cell death, provoking the onset of accelerated premature aging and cancer [24]. The common belief that oxidative stress can critically weaken the antioxidant defense system of diabetics has been the center of focus amongst the medical community. The healthful role of natural dietary antioxidants has been discredited in the past, but accumulating evidence obtained from both animal and human experimental models has clearly demonstrated their efficacy to counteract the deleterious effects of oxidative stress in major organs. Compared to conventional anti-diabetes drug therapies, many locally-grown phytonutraceuticals that possess eminent antioxidant powers and exert minimum toxicity are relatively cheap to process, thus offering economically feasible treatment options that can be made accessible worldwide. FPP is one such health product that has gained some criticism, despite overwhelming evidence to support its potential to be an adjunct for the dietary management of oxidative stress in many disease states, as will be highlighted further in this review.

\subsection{Interaction of FPP at the Physiological and Organ System Levels in Diabetes}

Although an increasing number of plants are being scientifically documented for their anti-hyperglycemic, antioxidant, and insulin stimulating activities [25], scientific evidence supporting the anti-diabetic properties of Carica papaya is now accumulating. The anti-hyperglycemic effect of papaya is thought to target pancreatic $\beta$ cells by improving their sensitivity to insulin, at the same time inhibiting $\alpha$-amylase and $\alpha$-glucosidase, a response which bears much resemblance to a second-generation sulfonylurea called glibenclamide [26]. Indeed, there exist many anti-hyperglycemic drugs that normalize plasma glucose levels, but there is a dearth of drugs that show the simultaneous correction of blood glucose, lipid, and antioxidant profiles. Interest in the investigation of the hypoglycemic properties of FPP in diabetic patients was initially investigated by Danese et al. [27] in an open randomized clinical trial in which $3 \mathrm{~g}$ FPP/day/2 months was reported to significantly reduce fasting and post-meal glucose levels in both normal and type 2 diabetic patients. These findings were further supported by Collard and Roy [28], where FPP $(0.2 \mathrm{~g} / \mathrm{kg}$ BW/8 weeks) was also found to attenuate the gain in blood glucose in $\mathrm{db} / \mathrm{db}$ mice. Although these findings do not directly prove the anti-diabetes activity of FPP, they are nonetheless consistent with the hypothesis that FPP can be administrated as an adjuvant treatment option to work in synergy with oral hypoglycemic drugs. While most diabetes-related clinical trials focus on single-target drugs, only a small percent of them are concerned with diabetes prevention, screening, or health maintenance [29]. Diabetes care organizations such as the International Diabetes Federation and American Diabetes Association continuously argue that researchers should prioritize finding more innovative preventive strategies that can work safely in conjunction with conventional diabetes therapies to improve their bioefficacy. In this context, a randomized clinical trial was conducted by our team to accelerate the translation of findings obtained from antioxidant assays conducted on fermented papaya preparation [30-32]. The results of our clinical study demonstrated that a daily supplementation of FPP for three months could improve the general total antioxidant status of pre-diabetic adults (Figure 1) and reduce carbonyl protein levels in plasma [31,33] (Figure 2). In addition, changes in liver biomarkers AST and ALT were also observed [33]. This trend was along the line of findings reported by Santiago et al. [34], who also saw the normalization of ALT and AST by FPP consumption. Elevated enzymes such as ALT, and to a lesser 
extent AST, can provide insight into the pathology of the liver since it is one of the most susceptible organs to oxidative-related cellular damage, thus helping to predict the risk of developing type 2 diabetes or non-alcoholic fatty liver disease-both of which are on the rise amongst adults within the age range tested [35]. As with all in-vivo studies, a note of caution is required when extrapolating data from clinical studies as drawbacks such as short observation periods, small sample sizes, compliance issues, and differences in analytical techniques need to be considered whilst interpreting findings. However, despite this, it is recommended that medical organizations integrate a variety of such biomarkers into their routine screening exercise protocols for better identification and tracking of at-risk individuals.

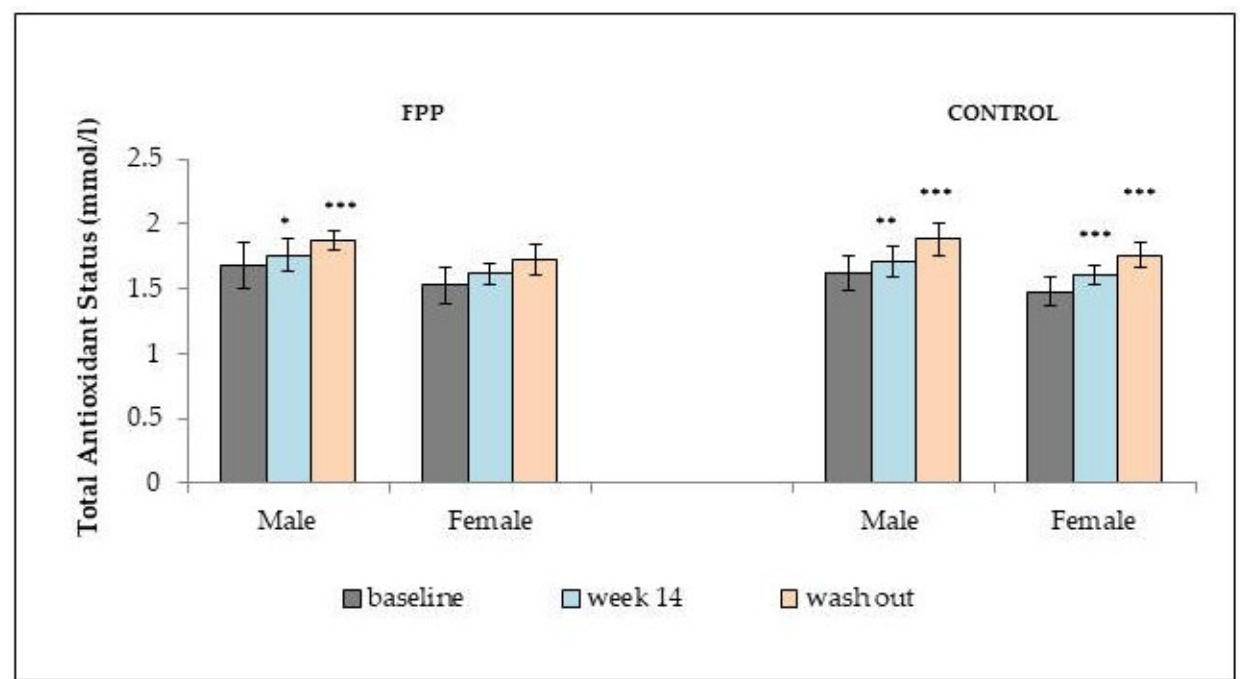

Figure 1. Effect of the total antioxidant (TAS) status in a pre-diabetic population under the FPP $(N=36)$ and control regimes $(N=53)$. Data is expressed as mean TAS value $(\mathrm{mmol} / \mathrm{L})$, where error bars represent standard deviation. ${ }^{*} p<0.05,{ }^{* *} p<0.01,{ }^{* * *} p<0.001$ vs. baseline. Reproduced with permission from Somanah et al. [33], Journal of Preventive Medicine; published by Elsevier, 2012.

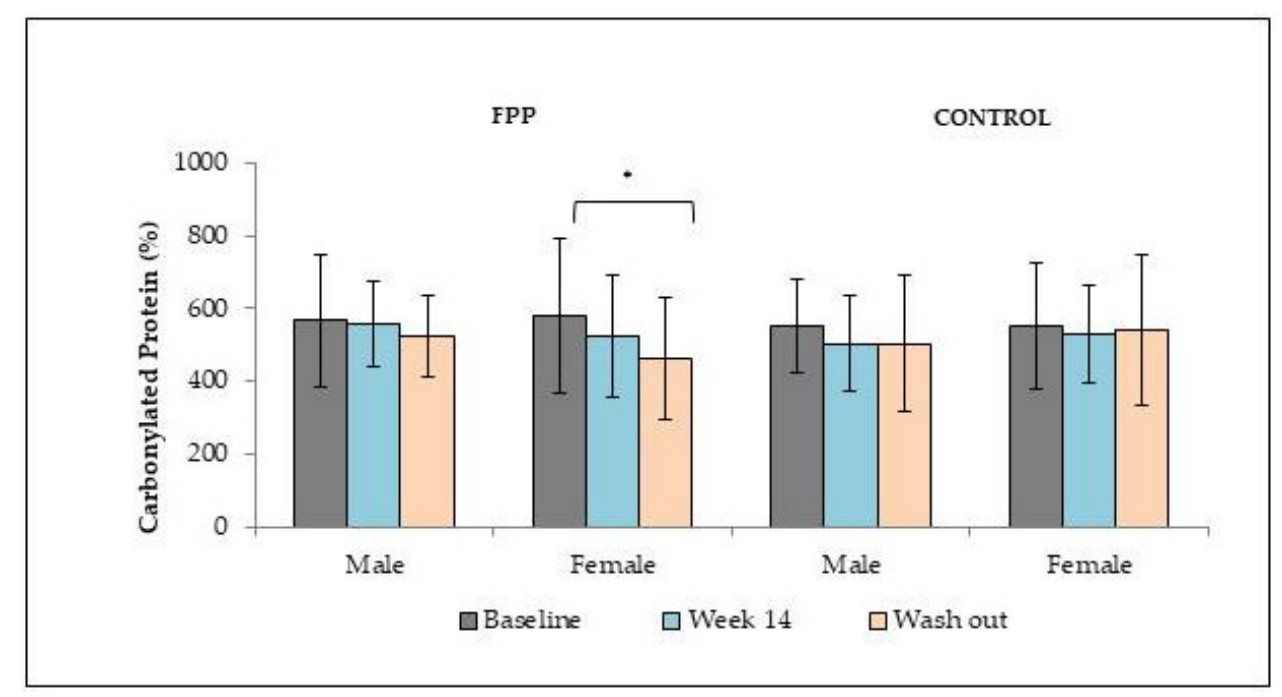

Figure 2. The effect of fermented papaya preparation (FPP) on carbonyl protein accumulation as a percentage compared to control $(1 \% \mathrm{NaCl})$ in a pre-diabetic population under the FPP $(N=41)$ and control regimes $(N=58)$; error bars represent standard deviation. ${ }^{*} p<0.05$ vs. baseline. Reproduced with permission from Somanah et al. [31], Food and Chemical Toxicology; published by Elsevier, 2014. 


\subsection{Anti-Inflammatory and Immuno-Modulatory Effects of FPP in Diabetic Conditions}

An observational study published in the American Journal of Human Genetics by Holmes et al. [36] claimed that "for every $1 \mathrm{~kg} / \mathrm{m}^{2}$ gain in body mass index (BMI), the risk of developing type 2 diabetes increases by $27 \%$ " - supporting the notion that type 2 diabetes is a direct outcome of high BMI and increased abdominal fat mass - two major characteristics of obesity which have been linked to sub-clinical inflammatory states in the adipose tissue [37]. In an attempt to understand the influence of oxidative stress on the metabolic response of adipocytes in the presence of papaya, our team used an in vitro cellular model to mimic the micro-environment of metabolic overload by mitochondrial oxidative stress. Using an extract of Mauritian Carica papaya (var. Solo), fruit extracts were found to significantly reduce oxidative stress levels within human pre-adipocytes (SW-872). The maintenance of mitochondrial viability, reduction of intracellular reactive oxygen species levels, and mediation of pro-inflammatory cytokine secretory levels (TNF-a, IL-6, MCP-1) were confirmation of papaya's diverse cytoprotective effects against oxidative-inflammation [38]. Similar trends have also been reported in literature for FPP. Papain isolated from the latex of unripe papaya pulp is documented for its anti-bacterial and fibrinolytic properties and used in wound care and chronic skin ulcer therapy for diabetics [39]. In a study by Collard and Roy [28], the authors found that FPP could also accelerate wound healing in $\mathrm{db} / \mathrm{db}$ mice through its elevation of nitric oxide levels, IL-6, TNF- $\alpha$, and circulating CD38 at the wound site. Moreover, unexpected surges in TNF- $\alpha$ within SW-872 cells and RAW 269.7 macrophages have been noted by Somanah et al. [38] and Rimbach et al. [6] under immunocompromised states, which were consequently attenuated by FPP. Taken together, these findings suggest that FPP does have unique immunoregulatory effects that can be indicative of its immune system enhancement properties. The gap of knowledge in this area warrants the imperative need to understand its mechanism of action at the molecular level in order for us to support its clinical efficacy claims.

\section{Attenuating Type 2 Diabetes Associated Diseases Using the Anti-Oxidant Properties of FPP}

At the genomic level, the interaction between oxidative stress mechanisms and chronic inflammation is highly complex, but they are agreed to play pivotal roles in the pathophysiology of diabetes [40]. Therapeutic interventions involving antioxidants could theoretically reduce the risks of base mutations and vulnerability of cells to undergo cell transformation, and lower the susceptibility of erythrocytes to undergo hemolysis reduced during diabetes. The ability of FPP to counteract oxidative stress in human erythrocytes was proven in a randomized supplementation study, where a dose of $6 \mathrm{~g}$ FPP/day for a period of 14 weeks clinically reduced the rate of haemolysis and accumulation of protein carbonyls (in-vivo indices of oxidative stress) in the blood plasma of pre-diabetic adults [31] (Figure 2). This finding compliments that reported in Raffaelli et al. [41], where FPP improved platelet function, by enhancing $\mathrm{Na}^{+} / \mathrm{K}^{+}$-ATPase activity and membrane fluidity, and ameliorated the antioxidant system functionality, through an increase in total antioxidant capacity and SOD activity, and a parallel decrease in conjugated diene levels in patients with type 2 diabetes. Moreover, through a multitude of in-vitro assays, our group has also demonstrated that FPP exhibits potent free radical scavenging potentials that are consistent with those ascribed to FPP in literature [31]. Such positive outcomes strongly suggest FPP to be a therapeutic functional food that can improve the integrity and quality of blood products in pre-diabetics and diabetics.

Taking the electron spin resonance data of Aruoma et al. [42] and Yoshino et al. [43] into consideration, the antioxidant activity of FPP was originally ascribed to its hydroxyl scavenging and iron chelating properties, but this theory has been further extended to its modulatory effects of mitogen-activated protein kinases (MAPKs) and the modification of key antioxidant enzymes such as glutathione peroxidase, SOD, 8-oxoguanine glycosylase, and heme oxygenase 1, amongst others [42,44], and also its polyphenols. Polyphenols have been heavily investigated for their roles in glucose metabolism and buffering against insulin resistance features. Nieto Calvache et al. [45] showed a mixture of soluble and insoluble dietary fibers along with carotenoids, ascorbic acid, 
and phenolic compounds to be present in papaya, providing evidential support to the characterization of FPP, as reported by [30]. Furthermore, the intestinal bioavailability of these polyphenols in a dietary fibre concentrate was capped to have $65 \%$ similarity to the pharmacokinetic properties of the diabetic drug metformin [46]. On a broader scale, components of the Carica papaya have been found to decrease serum glucose, triglycerides, and transaminases in STX-induced diabetic rats [47] and positively influence vascular functions and reduce insulin resistance in human subjects [48]. Studies by Martini et al. [49] have shown the ability of polyphenols in upregulating the transcriptional activity of paraoxonase I (PON1), potentially via its protective effects against oxidative stress-induced inactivation, hence altering the pathophysiological processes of diabetes. Other intricate mechanisms have associated polyphenols with improved insulin sensitivity via AMPK activation and the modulation of energy sensors [50]; downregulation of $m I R N A-335$ expression to improve insulin signaling and lipid metabolism via the disinhibition of genes such as InsR, Irs1, Sirt1, Prkaa1, Ppargc1a, Ppara, Lpl, Foxo1, and Gsk3b [51].

FPP exhibits enormous potential towards a more holistic approach in the treatment of diabetes-associated diseases. Combination therapy using metformin and ascorbic acid has been effective in the reduction of depressive behaviors by decreasing corticosterone levels via AMPK pathways in the hypothalamic-pituitary-adrenal axis and inducing a decrease in pro-inflammatory cytokines such as TNF- $\alpha$ and IL- 6 , which are also linked to neurological disorders and endothelial dysfunction [52].

\section{Oral Health Challenges Amongst the Diabetic Community: Examining the Anti-Cariogenic Potential of FPP}

The occurrence of dental caries amongst diabetics is a major health concern, especially when considering the high costs involved in the treatment and management of oral health. Consensus from epidemiological reports is that there has been a sharp increase in the prevalence of oral health complications amongst type 2 diabetics, particularly cases of dental caries, periodontitis, and halitosis [53]. Given the frequency at which these disorders occur amongst the diabetic population, they are now recognized to be part of a multitude of secondary complications manifested during uncontrolled diabetes. The histopathological evidence of the influence of high blood glucose levels on dental caries formation gathered from studies using animal models of diabetes such as alloxan-induced F344 rats [54], WBN/KObSIC rats [55], and db/db mice [56] is evidence of this. Based on the work of Campbell et al. [57], which demonstrated the different types of sugars present in the saliva of diabetics, included lactose, sucrose, fructose, maltose, sorbose, arabinose, and galacturonic acid. It is understood that many of these sugars will remain unnaturally high in the blood of those suffering from uncontrolled diabetes, making the elimination of biofilms difficult [58]. This could explain why diabetics are more susceptible to oral caries, bad breath, and reoccurring mouth infections compared to non-diabetics (Figure 3). Hence, in quest for innovative methods to maintain good oral health of diabetics, researchers have integrated plant extracts into toothpaste, mouthwash, and chewing gum formulations. The use of natural plant-based products for the dietary control and prevention of tooth decay is now favored [59]. However, despite numerous in-vitro studies, only a handful of plants reach clinical testing phases due to their limited effectiveness, stability, taste, and economic feasibility.

Based on Figure 3, recognition of the positive correlation between high levels of blood glucose, inflammatory responses, and the progression of dental caries allows us to theoretically assume that a reduction of key microorganisms in the dental biofilm community is a step towards the reestablishment of oral health in diabetics. This theory was the basis of a study by our group where FPP was examined for its anti-caries properties [30]. Using in vitro simulation models of dental plaque bacterial growth and the hydrophobicity of three opportunistic bacteria, namely S. mutans, S. mitis, and L. acidophilus, these bacteria were observed to decrease upon exposure to FPP, suggesting that low doses of this dietary health product may be a suitable candidate to complement good oral hygiene practices [30]. The fine powdery consistency of FPP in combination with its high dissolvability not only facilitates its consumption, but also stimulates the secretion of copious quantities of saliva in the mouth. 
Walsh et al. [60] claim that saliva has a buffering effect on oral biofilms. The secretion of copious amounts of saliva in the mouth by FPP would therefore imply the rapid clearance of large food debris and encourage the buccal $\mathrm{pH}$ to return to the baseline. In a study by Fibach and Ginsburg, the authors pointed out that an individual's oxidative stress level has an influential role to play in the health status of their oral cavity. Employing two highly sensitive luminol-dependent chemiluminescence assays, the authors demonstrated that under pathological conditions, FPP could easily dissolve in saliva or red blood cells to augment their antioxidant capacities [7]. The study conducted by our group and reported in Somanah et al. [33] clearly supports this theory, and hence FPP may have a role in oral health benefits. Interestingly, one previous study has reported that the consumption of FPP indeed led to an increased rate of salivary secretions high in IgA and phase II enzymes [61]. With regards to periodontitis in diabetics (a chronic bucal infection largely caused by the pathogen Porphyromonas gingivalis), the detection of abnormal levels of TNF- $\alpha$, IL-6, IL-1 $\beta$, and CRP in gingival fluid and tissue indicates that this condition is characterized by chronic inflammation which is hypothesized to lead to the progressive destruction of the tissues supporting the teeth, cementum, and alveolar bone. In a recent open randomized study, Russian investigators proved the clinical efficacy of a fermented papaya gel against periodontitis. Topical administration of this gel was observed to lead to a considerable improvement of major indices of disease severity, such as reduced bleeding and gingival pocket depth, and the normalization of IL-10, IL-6, and IL-1 $\beta$ cytokine levels after 14 days of application, all of which may be of direct relevance to diabetics (Figure 3). Although the exact mechanism has yet to be understood, the authors speculate that FPP can work in synergy with human granulocytes to enhance the phagocytosis of key microorganisms present in gingival tissues [62].

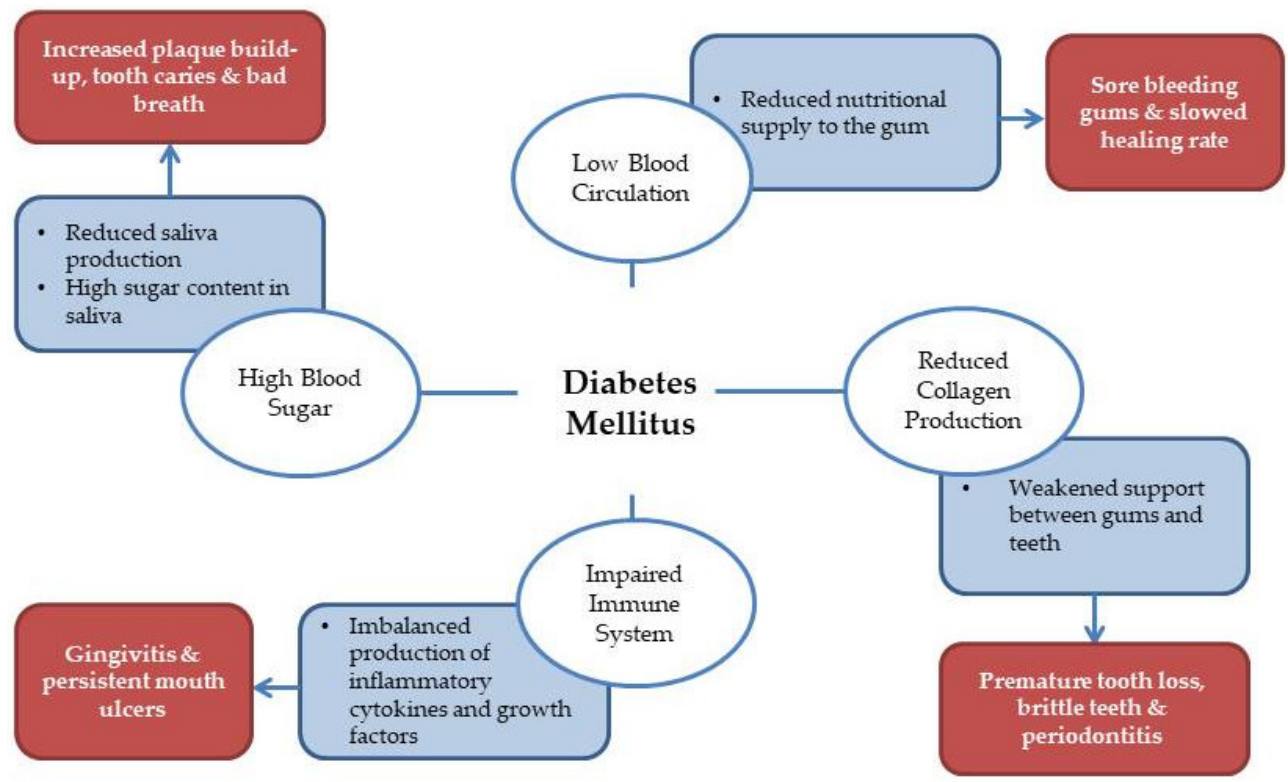

Figure 3. Common reasons as to why diabetics are prone to developing oral health issues.

Unfortunately, the lack of studies investigating the anti-cariogenic potential of FPP renders a comparative discussion of its possible mechanisms of action difficult. Attention has instead been given to papain-containing formulations from fresh fruit extracts [63] as their nutritional and biochemical composition is thought to be less complex than that of FPP. The anti-cariogenic activity of papain has been observed to be highly selective, only acting upon carious tissue, which does not express genes encoding for a plasmatic protease inhibitor: alpha 1 anti-trypsin [63]. Whether this characteristic can be observed by FPP remains to be explored. Nevertheless, papaya-based products show a promising perspective for future studies in the area of phytodentistry. 


\section{Appreciating the Anti-Cancer Effects Precipitated by FPP}

Despite large investments made in the area of cancer prevention, the escalating prevalence of cancer amongst diabetics clearly indicates that the present success rate of clinical therapies is low. One prominent explanation for this is that preclinical research on anti-cancer drugs is flawed, in the sense that it overlooks treating the fundamental cause of cancer: oxidative stress. Recognition between prolonged oxidative-inflammatory insults during diabetes as the etiology of cancer has sparked our interest in searching for natural but innovative anti-cancer agents. Understanding how the diabetes micro-environment can predispose one to the onset of cancer has been reviewed by our group in Aruoma et al. [64], bringing forward the concept that ROS- and cytokine-dependent signaling pathways represent a specific vulnerability that can be selectively targeted by antioxidants. Novel bioactive components such as benzyl glucosinolate, which exhibit anti-growth activities on several tumor cell lines, have been identified in papaya [65]. The review paper of Nguyen et al. [66] explores the anticancer activities attributed to organic extracts of papaya.

In light of the previous sections which lengthily discuss the pertinence of FPP to modulate biomarkers of oxidative stress and inflammation within cell-based models, the eventual goal of our group was to shed light on the anti-cancer propensity of the papaya-based product-FPP. Common combinational therapies include surgery, chemotherapy, radiation, and immunosuppressant drugs, which are deemed effective, but highly aggressive. Unpleasant side-effects such as acute headaches, vomiting, nausea, and occasional bouts of unconsciousness are commonly experienced by patients. Also, with exposure to high levels of ionizing radiation, severe oxidative stress can increase the patient's risk to structural damage of the skin, spermatogia, and hematopoietic stem cells, amongst others [67-69]. A group of Russian researchers was amongst the first to notice a positive effect upon the regular consumption of FPP in children undergoing radiotherapy [70], notably in terms of the attenuation of unpleasant side effects associated with aggressive radiotherapy. Referring to published findings of our group in the Journal Life Sciences, the seminal research work of Somanah et al. used the $N$-methyl- $N$-nitrosourea (MNU)-injected balb/c mice model to explore the modulatory effect of FPP against MNU-induced hepatocellular carcinoma [71]. Amongst all doses tested, mice of the $500 \mathrm{mg}$ FPP $/ \mathrm{kg}$ BW group were found to benefit the most from this treatment. Reduced shedding of hair, improved alertness, and a gain in both weight and appetite were noted. Moreover, from a haematological point-of-view, compared to the control group, a subsequent drop of nearly $31 \%$ in the haemoglobin level was noted, undoubtedly caused by excessive free radical attack on vulnerable erythrocytes and phase II detoxifying/antioxidant enzymes. Fractions of whole blood such as hemoglobin concentrations, and leukocyte and platelet counts were found to normalize. This is a possible indication of the counter-occurrence of MNU-induced hemolysis by FPP. Furthermore, the platelet count in MNU control mice remained exceptionally high, which was indicative of the formation of metastatic lesions within the liver. This was visually confirmed by the appearance of red, swollen, and inflamed growths on the abdominal area of treated mice. In this study [71], circulating malondialdehyde (MDA) levels (a toxic product of lipid peroxidation which is considered to be indirect tumor promoter and co-carcinogenic agent) were observed to drop (Figure 4), together with simultaneous augmentations in enzymatic SOD $(+20 \%)$, CAT $(+81 \%)$, and GPx $(+66 \%)$ release in FPP-supplemented mice. These findings coincide with similar trends reported previously [44,70,72]. 

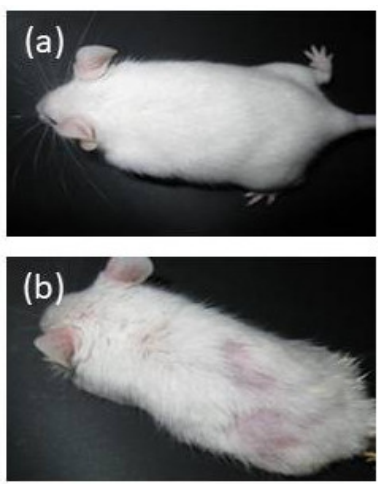

(c)

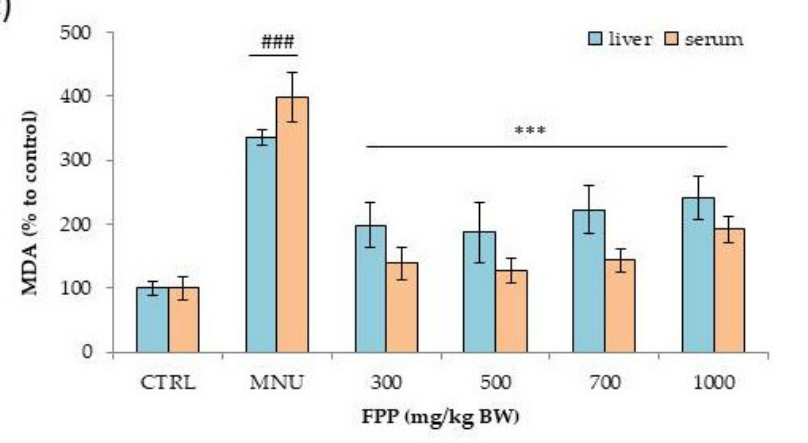

Figure 4. (a) Physical appearance of balb/c mice from the PBS control group and (b) $N$-methyl-N-nitrosourea (MNU) control group. (c) Malondialdehyde (MDA) levels in fermented papaya preparation (FPP)-supplemented balb/c mice treated with or without MNU. Data is presented as the mean of five replicates, where error bars represent \pm standard deviation. \#\#\# $p<0.001$ vs. PBS control; ${ }^{* * *} p<0.001$ vs. MNU control. Reproduced with permission from Somanah et al. [71], Life Sciences; published by Elsevier, 2016.

Although no profound molecular studies have been conducted on FPP to explain how it achieves these outcomes, some theories have been put forward through the use of genotoxins like MNU, benzo(a)pyrene, Fe-NTA, and $\mathrm{H}_{2} \mathrm{O}_{2}$, which are documented to attack DNA and distort its stability through two basic pathways: either by reaction with a DNA nucleophile or electrophile, or by reaction with the pi $(\pi)$ or $\mathrm{C}-\mathrm{H}$ bonds located within nucleotides. This is evidenced by increased peak intensities at 1190, 1254, 1322, 1405, 1152, and $1463 \mathrm{~cm}^{-1}$ using Raman laser spectroscopy (Figure 5) [73]. In a unique study, our group utilized Raman laser spectroscopy for the first time to detect any reversal of structural alterations (damage) inflicted by MNU on DNA by FPP. Data showed the reduction in the intensity of peaks at regions corresponding to nucleotide bases or to the phosphodiester backbone (Figure 5) [71]. This provides sufficient evidence that FPP can indeed protect DNA through radical scavenging, as proposed in an earlier study by Aruoma et al. [5] and Rimbach et al. [6]. Molecular data suggests that FPP reduces the extent of DNA damage by enhancing the activation of ERK, p35, and Akt. Such protein kinases are activated in response to DNA damage, providing a cellular signal to DNA repair enzymes (e.g., hOGG1), survival proteins (e.g., bcl-2), cell cycle control factors (e.g., cyclin D1), and several transcription factors $[5,44]$. FPP is also thought to divert hydroxyl radicals away from the $\pi$ bonds of C5-C6 pyrimidines and N8-N7 or C4-C8 bonds of purines-thus protecting the vulnerable areas of DNA from any major structural alterations $[43,74]$.

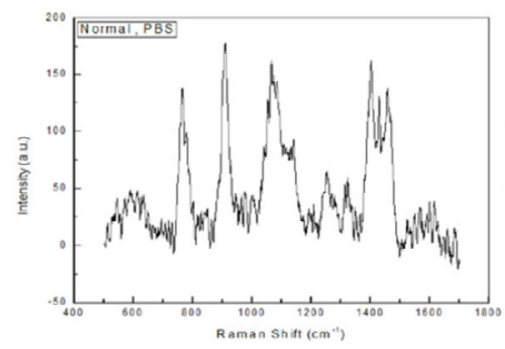

(a)

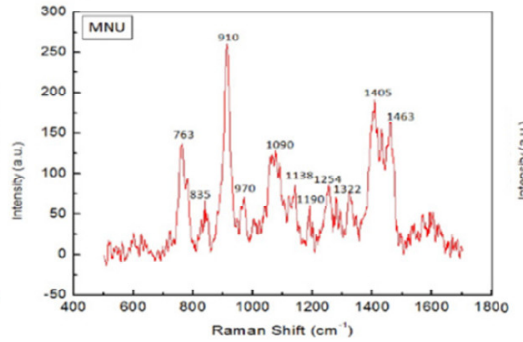

(b)

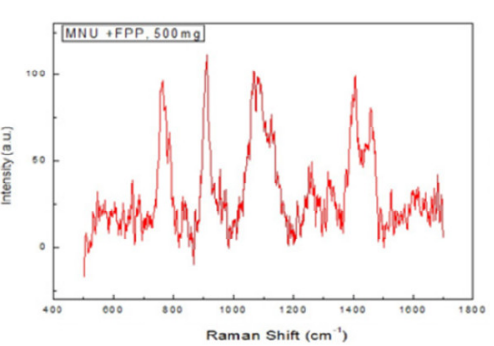

(c)

Figure 5. Comparison of Raman laser spectra of liver DNA in the region of $400-1700 \mathrm{~cm}^{-1}$ for all experimental groups: (a) PBS control, (b) MNU control, (c) MNU + $500 \mathrm{mg} \mathrm{FPP/kg} \mathrm{BW.} \mathrm{Data} \mathrm{is}$ representative of eight replicates. [Parameters: resolution $\mathrm{cm}^{-1}$, step of $100 \mathrm{~nm}$, laser power $5 \mathrm{~mW}$, exciting source $514.5 \mathrm{~nm}$ argon ion laser]. Reproduced with permission from Somanah et al. [71], Life Sciences; published by Elsevier, 2016. 
The results of the study reported in Somanah et al. [71] clearly suggest that FPP can simultaneously boost the recovery of the immune defense system, hinder DNA damage, and reduce symptoms of ill health associated with aggressive carcinoma. The increased longevity of our test model mice undoubtedly proves that liver cancer can be managed to some extent without any harsh medical intervention. To date, the hepatoprotective effects of FPP have not been explored using this animal model with MNU as a tumorigen. These findings are therefore of great importance to the field of phytochemotherapy. Furthermore, no adverse effects have been noted in the literature to date regarding the consumption of FPP —-deeming it safe for both adults and children. Extrapolation of the observations discussed in this paper and those reported by our group thus appraise fermented papaya preparation to be a remarkable yet feasible phytonutraceutical which can be used to prevent or manage diseases governed by chronic oxidative stress, especially diabetes and cancer.

\section{Conclusions}

Discussions included within this review converge to the bottom line that free radicals do indeed contribute to the surge in chronic diseases in individuals who are burdened by uncontrolled oxidative stress. Studies on FPP have been overlooked by some researchers, as several findings appear inconclusive due to the lack of supplementary evidence of its composition. Nonetheless, the expansive evidence gathered over the past decade presents FPP as an intriguing yet promising health supplement that deserves greater attention from the scientific community. Efforts now need to be steered towards the elucidation of its composition and its mechanistic approach in the diseased micro-environment in order to appreciate its true potential.

Author Contributions: J.S., M.P., O.I.A., and T.B. wrote/reviewed/edited the manuscript.

Funding: The Authors acknowledge the financial support from the Mauritius Research Council under the National Research and Innovation Chair program of T.B.

Conflicts of Interest: O.I.A. is actively involved in biomedical research involving fermented papaya preparation for the Osato Research Institute, Gifu, Japan.

\section{References}

1. Ghosh, D.; Chattopadhyay, P. Preparation of idli batter, its properties and nutritional improvement during fermentation. J. Food Sci. Technol. 2011, 48, 610-615. [CrossRef] [PubMed]

2. Tsukamoto, Y.; Ichise, H.; Kakuda, H.; Yamaguchi, M. Intake of fermented soybean (natto) increases circulating vitamin $\mathrm{K}_{2}$ (menaquinone-7) and gamma-carboxylated osteocalcin concentration in normal individuals. J. Bone Miner. Metab. 2000, 18, 216-222. [CrossRef] [PubMed]

3. Dinesh Babu, P.; Bhakyaraj, R.; Vidhyalakshmi, R. A low-cost nutritious food "Tempeh"-A review. World J. Diary Food Sci. 2009, 4, 22-27.

4. Montagnac, J.; Davis, C.; Tanumihardjo, S. Processing Techniques to Reduce Toxicity and Anti nutrients of Cassava for Use as a Staple Food. Compr. Rev. Food Sci. Food Saf. 2009, 8, 17-27. [CrossRef]

5. Aruoma, O.I.; Yuki, H.; Marotta, F.; Mantello, P.; Rachmilewitz, E.A.; Montagnier, L. Applications and bioefficacy of the functional food supplement fermented papaya preparation. Toxicology 2010, 278, 75-87. [CrossRef] [PubMed]

6. Rimbach, G.; Park, Y.C.; Guo, Q.; Moini, H.; Qureshi, N.; Saliou, C.; Takayama, K.; Virgili, F.; Packer, L. Nitric oxide synthesis and TNF-alpha secretion in RAW 264.7 macrophages: Mode of action of a fermented papaya preparation. Life Sci. 2000, 67, 679-694. [CrossRef]

7. Fibach, E.; Ginsburg, I. The Antioxidant Effect of Fermented Papaya Preparation in the Oral Cavity. Phytother. Res. 2015, 29, 1317-1322. [CrossRef] [PubMed]

8. Fujita, Y.; Tsuno, H.; Nakayama, J. Fermented Papaya Preparation Restores Age-Related Reductions in Peripheral Blood Mononuclear Cell Cytolytic Activity in Tube-Fed Patients. PLoS ONE 2017, 12, e0169240. [CrossRef] [PubMed]

9. Maisarah, A.M.; Asmah, R.; Fauziah, O. Proximate analysis, antioxidant and antiproliferative activities of different parts of Carica papaya. J. Nutr. Food Sci. 2014, 4, 267. 
10. Luximon-Ramma, A.; Bahorun, T.; Crozier, A. Antioxidant actions and phenolic and vitamin C contents of common Mauritian exotic fruits. J. Sci. Food Agric. 2003, 83, 496-502. [CrossRef]

11. Simirgiotis, M.J.; Caligari, P.D.S.; Schmeda-Hirschmann, G. Identification of phenolic compounds from the fruits of the mountain papaya Vasconcellea pubescens A. DC. grown in Chile by liquid chromatography-UV detection-mass spectrometry. Food Chem. 2009, 115, 775-784. [CrossRef]

12. Moussa, S.A. Oxidative stress in diabetes mellitus. Rom. J. Biophys. 2008, 18, 225-236.

13. Valko, M.; Leibfritz, D.; Moncol, J.; Cronin, M.T.; Mazur, M.; Telser, J. Free radicals and antioxidants in normal physiological functions and human disease. Int. J. Biochem. Cell Biol. 2007, 39, 44-84. [CrossRef] [PubMed]

14. Dröge, W. Free radicals in the physiological control of cell function. Arch. Biochem. Biophys. 2002, 430, 37-48. [CrossRef] [PubMed]

15. Bagchi, K.; Puri, S. Free radicals and antioxidants in health and disease. East Mediterr. Health J. 1998, 4, 350-360.

16. Rains, J.L.; Jain, S.K. Oxidative stress, insulin signaling, and diabetes. Free Radic. Biol. Med. 2011, 50, 567-575. [CrossRef] [PubMed]

17. Butler, A.E.; Janson, J.; Bonner-Weir, S.; Ritzel, R.; Rizza, R.A.; Butler, P.C. Beta-cell deficit and increased beta-cell apoptosis in humans with type 2 diabetes. Diabetes 2010, 52, 102-110. [CrossRef]

18. Finegood, D.T.; Mcarthur, M.D.; Kojwang, D.; Thomas, M.J.; Topp, B.G.; Leonard, T.; Buckingham, R.E. Beta-cell mass dynamics in Zucker diabetic fatty rats. Rosiglitazone prevents the rise in net cell death. Diabetes 2001, 50, 1021-1029. [CrossRef] [PubMed]

19. Solomon, T.P.; Haus, J.M.; Kelly, K.R.; Rocco, M.; Kashyap, S.R.; Kirwan, J.P. Improved pancreatic beta-cell function in type 2 diabetic patients after lifestyle-induced weight loss is related to glucose-dependent insulinotropic polypeptide. Diabetes Care 2010, 33, 1561-1566. [CrossRef] [PubMed]

20. Hood, M.S.; Little, J.P.; Tarnopolsky, M.A.; Myslik, F.; Gibala, M.J. Low-volume interval training improves muscle oxidative capacity in sedentary adults. Med. Sci. Sports Exerc. 2011, 43, 1849-1856. [CrossRef] [PubMed]

21. Fowler, M.J. Microvascular and macrovascular complications of diabetes. Clin. Diabetes 2008, 26, 77-82. [CrossRef]

22. Mshelia, D.S. Role of free radicals in pathogenesis of diabetes nephropathy. Ann. Afr. Med. 2004, 3, 55-62.

23. Oloffson, E.A.; Marlund, S.L.; Behnoig, A. Enhanced diabetes induced cataract in copper zinc superoxide dismutase-null mice. Investig. Ophthalmol. Vis. Sci. 2009, 50, 2913-2918. [CrossRef] [PubMed]

24. Aruoma, O.I. Free radicals, oxidative stress, and antioxidants in human health and disease. J. Am. Oil. Chem. Soc. 1998, 75, 199-212. [CrossRef]

25. Pandeya, K.B.; Tripathi, I.P.; Mishra, M.K.; Dwivedi, N.; Pardhi, Y.; Kamal, A.; Gupta, P.; Dwivedi, N.; Mishra, C. A Critical Review on Traditional Herbal Drugs: An Emerging Alternative Drug for Diabetes. Int. J. Org. Chem. 2013, 3, 1-22. [CrossRef]

26. Oboh, G.; Olabiyi, A.A.; Akinyemi, A.J.; Ademiluyi, A.O. Inhibition of key enzymes linked to type 2 diabetes and sodium nitroprusside-induced lipid peroxidation in rat pancreas by water-extractable phytochemicals from unripe pawpaw fruit (Carica papaya). J. Basic Clin. Physiol. Pharmacol. 2013, 30, 1-14. [CrossRef] [PubMed]

27. Danese, C.; Espoisto, D.; D’alfonso, V.; Civene, M.; Ambrosino, M.; Colotto, M. Plasma glucose level decreases as a collateral effect of fermented papaya preparation use. Clin. Ther. 2006, 157, 195-198.

28. Collard, E.; Roy, S. Improved function of diabetic wound site macrophages and accelerated wound closure in response to oral supplementation of a fermented papaya preparation. Antioxid. Redox. Signal 2010, 13, 599-606. [CrossRef] [PubMed]

29. Lakey, W.C.; Barnard, K.; Batch, B.C.; Chiswel, L.K.; Tasneem, A.; Green, J.B. Are current clinical trials in diabetes addressing important issues in diabetes care? Diabetologia 2013, 56, 1226-1235. [CrossRef] [PubMed]

30. Somanah, J.; Bourdon, E.; Bahorun, T.; Aruoma, O.I. The inhibitory effect of a fermented papaya preparation on growth, hydrophobicity, and acid production of Streptococcus mutans, Streptococcus mitis, and Lactobacillus acidophilus: Its implications in oral health improvement of diabetics. Food Sci. Nutr. 2013, 1, 416-421. [CrossRef] [PubMed] 
31. Somanah, J.; Bourdon, E.; Rondeau, P.; Bahorun, T.; Aruoma, O.I. Relationship between fermented papaya preparation supplementation, erythrocyte integrity and antioxidant status in pre-diabetics. Food Chem. Toxicol. 2014, 65, 12-17. [CrossRef] [PubMed]

32. Ghoti, H.; Rosenbaum, H.; Fibach, E.; Rachmilewitz, E.A. Decreased hemolysis following administration of antioxidant-fermented papaya preparation (FPP) to a patient with PNH. Ann. Hematol. 2010, 89, 429-440. [CrossRef] [PubMed]

33. Somanah, J.; Aruoma, O.I.; Gunness, T.K.; Kowelssur, S.; Dambala, V.; Murad, F.; Googoolye, K.; Daus, D.; Indelicato, J.; Bourdon, E.; et al. Effects of a short term supplementation of a fermented papaya preparation on biomarkers of diabetes mellitus in a randomized Mauritian population. J. Prev. Med. 2012, 54, S90-S97. [CrossRef] [PubMed]

34. Santiago, L.A.; Uno, K.; Kishida, T.; Miyagawa, F.; Osato, J.A.; Mori, A. Effect of Immun'Age on serum components and immunological functions in humans. Neurosciences 1994, 20, 149-152.

35. Trojak, A. Nonalcoholic Fatty Liver Disease in Patients with Type 2 Diabetes- Gender Differentiation in Determinants. J. Diabetes Metab. 2015, 6, 476. [CrossRef]

36. Holmes, M.V.; Lange, L.A.; Palmer, T.; Lanktree, M.B.; North, K.E.; Almoguera, B.; Buxbaum, S.; Chandrupatla, H.R.; Elbers, C.C.; GUO, Y.; et al. Causal effects of body mass index on cardiometabolic traits and events: A Mendelian randomization analysis. Am. J. Hum. Genet. 2014, 94, 198-208. [CrossRef] [PubMed]

37. Oh, D.Y.; Morinaga, H.; Talukdar, S.; Bae, E.J.; Olefsky, J.M. Increased macrophage migration into adipose tissue in obese mice. Diabetes 2012, 61, 346-354. [CrossRef] [PubMed]

38. Somanah, J.; Bourdon, E.; Bahorun, T. Extracts of Mauritian Carica papaya (var. solo) protect SW872 and HepG2 cells against hydrogen peroxide induced oxidative stress. J. Food Sci. Technol. 2017, 54, 1917-1927. [CrossRef] [PubMed]

39. Blakytny, R.; Jude, E. The molecular biology of chronic wounds and delayed healing in diabetes. Diabetic Med. 2006, 23, 594-608. [CrossRef] [PubMed]

40. Houstis, N.; Rosen, E.D.; Lander, E.S. Reactive oxygen species have a casual role in multiple forms of insulin resistance. Nature 2006, 440, 944-948. [CrossRef] [PubMed]

41. Raffaelli, F.; Nanetti, L.; Montecchiani, G.; Borroni, F.; Salvolini, E.; Faloia, E.; Ferretti, G.; Mazzanti, L.; Vignini, A. In vitro effects of fermented papaya (Carica papaya, L.) on platelets obtained from patients with type 2 diabetes. Nutr. Metab. Cardiovasc. Dis. 2015, 25, 224-229. [CrossRef] [PubMed]

42. Aruoma, O.I.; Colognato, R.; Fontana, I.; Gartlon, J.; Migliore, L.; Koike, K.; Coecke, S.; Lamy, E.; Mersch-Sundernann, V.; Laurenz, I.; et al. Molecular effects of a fermented papaya preparation on oxidative damage, MAP kinase activation and modulation of the benzo [a] pyrene mediated genotoxicity. Biofactors 2006, 26, 147-159. [CrossRef] [PubMed]

43. Yoshino, F.; Lee, M.C.I.; Kobayashi, K.; Hayashi, Y.; Aruoma, O.I. Assessment of the effect of a fermented papaya preparation on oxidative damage in spontaneously hypertensive rat (SHR) brain using electron spin resonance (ESR) imaging and L-band spectroscopy. J. Funct. Food 2009, 1, 375-380. [CrossRef]

44. Marotta, F.; Koike, K.; Lorenzetti, A.; Jain, S.; Signorelli, P.; Metugriachuk, Y.; Mantello, P.; Locorotondo, N. Regulating redox balance gene expression in healthy individuals by nutraceuticals: A pilot study. Rejuv. Res. 2010, 13, 175-178. [CrossRef] [PubMed]

45. Calvache, J.; Cueto, M.; Farroni, A.; De Escalada, P.M.; Gerschenson, L.N. Antioxidant characterization of new dietary fiber concentrates from Papaya pulp and peel (Carica papaya L.). J. Funct. Foods 2016, 27, 319-328. [CrossRef]

46. Scheen, A.J. Clinical pharmacokinetics of metformin. Clin. Pharmacokinet. 1996, 30, 359-371. [CrossRef] [PubMed]

47. Juárez-Rojop, I.E.; Tovilla-Zárate, C.A.; Aguilar-Domínguez, D.E.; Fuente, L.F.; Lobato-García, C.E.; Blé-Castillo, J.L.; López-Meraz, L.; Díaz-Zagoya, J.C.; Bermúdez-Ocaña, D.Y. Phytochemical screening and hypoglycemic activity of Carica papaya leaf in streptozotocin-induced diabetic rats. Rev. Bras. Farmacogn. 2014, 24, 341-347. [CrossRef]

48. Cao, H.; Wang, Y.; Xiao, J. Dietary Polyphenols and Type 2 Diabetes: Human Study and Clinical Trial. Free Radic. Biol. Med. 2017, 112, 158. [CrossRef]

49. Martini, D.; Del Bo', C.; Porrini, M.; Ciappellano, S.; Riso, P. Role of polyphenols and polyphenol-rich foods in the modulation of PON1 activity and expression. J. Nutr. Biochem. 2017, 48, 1-8. [CrossRef] [PubMed] 
50. Mutlur, K.R.; Carani, V.A. Polyphenols activate energy sensing network in insulin resistant models. Chem. Biol. Interact. 2017, 275, 95-107. [CrossRef] [PubMed]

51. Otton, R.; Bolin, A.P.; Ferreira, L.T.; Marinovic, M.P.; Rocha, A.L.S.; Mori, M.A. Polyphenol-rich green tea extract improves adipose tissue metabolism by down-regulating miR-335 expression and mitigating insulin resistance and inflammation. J. Nutr. Biochem. 2018, 57, 170-179. [CrossRef] [PubMed]

52. Shivavedi, N.; Kumar, M.; Tej, G.N.V.C.; Nayak, P.K. Metformin and ascorbic acid combination therapy ameliorates type 2 diabetes mellitus and comorbid depression in rats. Brain Res. 2017, 1674, 1-9. [CrossRef] [PubMed]

53. Bajaj, S.; Prasad, S.; Gupta, A.; Singh, V.B. Oral manifestations in type 2 diabetes and related complications. Indian J. Endocrinol. Metab. 2012, 16, 777-779. [CrossRef] [PubMed]

54. Nakahara, Y.; Sano, T.; Kodama, Y.; Ozaki, K.; Matsura, T. Allozan-induced hyoerglycemia causes rapid onset and progressive dental caries and periodontitis in F344 rats. Histol. Histopathol. 2012, 27, 1297-1306. [PubMed]

55. Kodama, Y.; Matsurura, M.; Sanyo, T.; Nakaraha, Y.; Ozaki, K.; Narama, I.; Matsuura, T. Diabetes enhances dental caries and apical periodontitis in caries susceptible WBN/KobSIc rats. J. Complement. Med. 2011, 61, 53-59.

56. Sano, T.; Matsuura, T.; Ozaki, K.; Narama, I. Dental caries and caries-related periodontitis in type 2 diabetic mice. Vet. Pathol. 2011, 48, 506-512. [CrossRef] [PubMed]

57. Campbell, M.J.A. Glucose in the saliva of the non-diabetic and the diabetic patient. Arch. Oral Biol. 1965, 10, 197-205. [CrossRef]

58. Loë, H. Periodontal disease: The sixth complication of diabetes mellitus. Diabetes Care 1993, 16, 329-334. [CrossRef] [PubMed]

59. Hotwani, K.; Baliga, S.; Sharma, K. Phytodentistry: Use of medicinal plants. J. Complement. Integr. Med. 2014, 11, 233-251. [CrossRef] [PubMed]

60. Walsh, L.J. Clinical dental plaque fermentation and its role in caries risk assessment. Int. J. Dent. 2006, 8, 34-40.

61. Marotta, F.; Naito, Y.; Jain, S.; Lorenzetti, A.; Soresi, V.; Kumari, A.; Carrera Bastos, P.; Tomella, C.; Yadav, H. Is there a potential application of a fermented nutraceutical in acute respiratory illnesses? An in-vivo placebo-controlled, cross-over clinical study in different age groups of healthy subjects. J. Biol. Regul. Homeost. Agents 2012, 26, 285-294. [PubMed]

62. Kharaeva, Z.F.; Zhanimova, LR.; Mustafaev, M.S.; De Luca, C.; Mayer, W.; Thai, J.C.S.; Tuan, R.T.S.; Korkina, L.G. Effects of Standardised Fermented Papaya Gel on Clinical Symptoms, Inflammatory Cytokines, and Nitric Oxide Metabolites in Patients with Chronic Periodontitis: An Open Randomized Clinical Study. Mediators Inflamm. 2016, 2016, 9379840. [CrossRef] [PubMed]

63. Bhardwaj, A.; Bhardwaj, S.V. Papacarie ${ }^{\circledR}$ containing papain: A natural chemomechanical caries removal agent. Res. J. Pharm. Biol. Chem. Sci. 2012, 3, 660-665.

64. Aruoma, O.I.; Neergheen, V.S.; Bahorun, T.; Jen, L.-S. Free Radicals, Antioxidants and Diabetes: Embryopathy, Retinopathy, Neuropathy, Nephropathy and Cardiovascular Complications. Neuroembryol. Aging 2006, 4, 117-137. [CrossRef]

65. Li, Z.-Y.; Wang, Y.; Shen, W.-T.; Zhou, P. Content determination of benzyl glucosinolate and anti-cancer activity of its hydrolysis product in Carica papaya L. Asian Pac. J. Trop. Dis. 2012, 5, 231-233. [CrossRef]

66. Nguyen, T.T.; Shaw, P.N.; Parat, M.O.; Hewavitharana, A.K. Anticancer activity of Carica Papaya: A Review. Mol. Nutr. Food Res. 2013, 57, 153-164. [CrossRef] [PubMed]

67. Bickers, D.R.; Athar, M. Oxidative stress in the pathogenesis of skin disease. J. Investig. Dermatol. 2006, 126, 2565-2575. [CrossRef] [PubMed]

68. Ahmadi, A.; Ng, S.-C. Fertilizing ability of DNA-damaged spermatozoa. J. Exp. Zool. 1999, $284,696-704$. [CrossRef]

69. Wang, Y.; Liu, L.; Pazhanisamy, S.K.; Li, H.; Meng, A.; Zhou, D. Total body irradiation causes residual bone marrow injury by induction of persistent oxidative stress in murine hematopoietic stem cells. Free Rad. Biol. Med. 2010, 48, 348-356. [CrossRef] [PubMed]

70. Korkindel, L.; Osato, J.A.; Chivilyema, I.; Samocravyova, E.; Cheremisina, Z.; Afanas'ev, I. Radioproetctive and antioxidant effects of zinc aspartate and fpp in aspartate and fpp in Children with acute myelo-iympholeukemia. Nutrition 1995, 11, 555-558. 
71. Somanah, J.; Ramsaha, S.; Verma, S.; Kumar, A.; Sharma, P.; Singh, R.K.; Aruoma, O.I.; Bourdon, E.; Bahorun, T. Fermented papaya preparation modulates the progression of n-methyl-n-nitrosourea induced hepatocellular carcinoma in Balb/C mice. Life Sci. 2016, 151, 330-338. [CrossRef] [PubMed]

72. Imao, K.; Wang, H.; Komatsu, M.; Hiramatsu, M. Free radical scavenging activity of fermented papaya preparation and its effect on lipid peroxide level and superoxide dismutase activity in iron-induced epileptic foci of rats. Biochem. Mol. Biol. Int. 1998, 45, 11-23. [CrossRef] [PubMed]

73. Verma, S.; Bahorun, T.; Singh, R.K.; Aruoma, O.I.; Kumar, A. Effect of aegle marmelos leaf extract on n-methyl n-nitrosourea-induced hepatocarcinogensis in Balb/C Mice. Pharm. Biol. 2013, 51, 1272-1281. [CrossRef] [PubMed]

74. Wood, C.D.; Thornton, T.M.; Sabio, G.; Davis, R.A.; Rincon, M. Nuclear localization of p38 MAPK in response to DNA damage. Int. J. Biol. Sci. 2007, 5, 428-437. [CrossRef]

(C) 2018 by the authors. Licensee MDPI, Basel, Switzerland. This article is an open access article distributed under the terms and conditions of the Creative Commons Attribution (CC BY) license (http://creativecommons.org/licenses/by/4.0/). 